\title{
Los Retos de la Infectología en Honduras
}

\section{The Challenges of Infectious Diseases in Honduras}

Luis Enrique Romero Reyes. *

En Honduras antes del 2015, se contaba con tres infectólogos pediatras, dos en la zona central y uno en la costa norte, todos empeñados en exigir en los hospitales donde laboraban los insumos necesarios para realizar el diagnóstico certero, supervisar y controlar el uso racional de la terapia antibiótica, disminuir la resistencia antimicrobiana, practicar el control y la prevención de infecciones asociadas a la atención de la salud (IAAS), entre otras cosas, todo ello para disminuir la morbimortalidad por enfermedades infecciosas.

Con la reciente llegada a nuestra Ciudad y Escuela de dos nuevos profesionales de la Infectología Pediátrica; de más está decir egresados del Posgrado en San Pedro Sula, robustece el endeble sistema que con precariedad ha sostenido una desigual lucha con las emergentes, recrudescentes y endémicas enfermedades infecciosas que abaten a países como el nuestro.

El Infectólogo necesita del apoyo de una amplia gama de herramientas de laboratorio, algunas con mayor complejidad que otras; por ejemplo cultivos, métodos automatizados, pruebas serológicas, reacción en cadena de polimerasa $(\mathrm{PCR})$, para lograr un diagnóstico acertado.

La mayoría de los hospitales tanto privados como públicos, no cuentan con métodos automatizados para la detección y sensibilidad de las bacterias aisladas, por lo que la detección, tipificación y sensibilidad se realiza mediante pruebas manuales, el único hospital que cuenta con sistema automatizado es el Hospital del Instituto Hondureño del Seguro Social.

Dirigir correspondencia a: luisromero706@gmail.com Recibido: 08 de agosto 2016 Aprobado: 12 de agosto 2016
En relación a las pruebas de detección viral, solo de realiza serología para algunos virus, pero no reacción en cadena de polimerasa. Teniendo en cuenta que la serología tiene escaso o ningún valor en el diagnóstico de infecciones virales, su diagnóstico en nuestro país se vuelve un verdadero reto.

Otro problema al cual frecuentemente se enfrenta el Pediatra o el Infectólogo en los hospitales públicos, es la carencia de antimicrobianos, tanto en variedad como en cantidad, esto sumado a la falta de medios automatizados para tipificación y sensibilidad a los distintos antimicrobianos, lo cual favorece fallas terapéuticas, pone en riesgo la vida del paciente y aumenta la resistencia a antibióticos.

Es un verdadero reto ejercer la infectología en Honduras debido al alto costo que implica, lo que hace del ejercicio de la Infectología en Honduras un verdadero reto, ya que día a día nos enfrentamos a patologías que requieren de un abordaje integral y moderno, con diagnóstico y tratamiento complejos; pero en vista de la limitación de recursos en el mejor de los casos todo se realiza en base a clínica y tratamiento empírico, esperamos en un futuro cercano que ésta situación mejore para beneficio de los pacientes, sus familias y la sociedad en general.

Sin embargo, no todo es negativo, recientemente se introdujo el GeneXpert ${ }^{\circledR}$ MTB/RIF, dicha prueba ya se realiza en los centros regionales de salud de nuestro país.

Aprovecho finalmente el presente número del Acta Pediátrica Hondureña para invitarlos al esfuerzo mancomunado para arrostrar los nuevos retos de la Infectología pediátrica moderna en nuestro país. 